\title{
Diversity in the ministry of chaplaincy in the South African Department of Correctional Services
}

\begin{tabular}{|c|c|}
\hline $\begin{array}{l}\text { Authors: } \\
\text { Maake J.S. M } \\
\text { Maxwell Mkh }\end{array}$ & $\begin{array}{l}\text { asango } \\
\text { athini }^{1}\end{array}$ \\
\hline $\begin{array}{l}\text { Affiliations: } \\
{ }^{1} \text { Department } \\
\text { Theology, Fac } \\
\text { Theology, Uni } \\
\text { Pretoria, Sout }\end{array}$ & $\begin{array}{l}\text { of Practical } \\
\text { ulty of } \\
\text { versity of } \\
\text { h Africa }\end{array}$ \\
\hline $\begin{array}{l}\text { Project leade } \\
\text { M.J.S. Masan } \\
\text { Project numb }\end{array}$ & $\begin{array}{l}\text { r: } \\
\text { go } \\
\text { er: } 02467526\end{array}$ \\
\hline $\begin{array}{l}\text { Description: } \\
\text { This research } \\
\text { project, 'Pastc } \\
\text { Trauma Couns } \\
\text { by Prof. Dr Ma } \\
\text { Department o } \\
\text { Theology, Fac } \\
\text { Theology, Uni } \\
\text { Pretoria. }\end{array}$ & $\begin{array}{l}\text { is part of the } \\
\text { ral Care and } \\
\text { selling', directed } \\
\text { aake Masango, } \\
\text { f Practical } \\
\text { ulty of } \\
\text { versity of }\end{array}$ \\
\hline $\begin{array}{l}\text { Correspondin } \\
\text { Maake Masan } \\
\text { maake.masan }\end{array}$ & $\begin{array}{l}\text { g author: } \\
\text { go, } \\
\text { go@up.ac.za }\end{array}$ \\
\hline $\begin{array}{l}\text { Dates: } \\
\text { Received: } 14 \text { J } \\
\text { Accepted: } 27 \\
\text { Published: } 02\end{array}$ & $\begin{array}{l}\text { uly } 2016 \\
\text { Sept. } 2016 \\
\text { Dec. } 2016\end{array}$ \\
\hline $\begin{array}{l}\text { How to cite th } \\
\text { Masango, M.J } \\
\text { M., 2016, 'Div } \\
\text { ministry of ch } \\
\text { South African } \\
\text { Correctional S } \\
\text { Teologiese Stu } \\
\text { a3748. http:// } \\
\text { org/10.4102/l }\end{array}$ & $\begin{array}{l}\text { is article: } \\
\text {.S \& Mkhathini, } \\
\text { ersity in the } \\
\text { aplaincy in the } \\
\text { Department of } \\
\text { ervices', HTS } \\
\text { dies } 72(4), \\
\text { 'dx.doi. } \\
\text { tts.v72i4.3748 }\end{array}$ \\
\hline $\begin{array}{l}\text { Copyright: } \\
\text { (C) 2016. The A } \\
\text { Licensee: AOS } \\
\text { is licensed unc } \\
\text { Creative Comr } \\
\text { Attribution Lic }\end{array}$ & $\begin{array}{l}\text { Authors. } \\
\text { IS. This work } \\
\text { der the } \\
\text { nons } \\
\text { ense. }\end{array}$ \\
\hline Read online: & \\
\hline 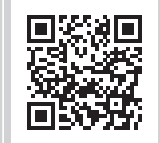 & $\begin{array}{l}\text { Scan this QR } \\
\text { code with your } \\
\text { smart phone or } \\
\text { mobile device } \\
\text { to read online. }\end{array}$ \\
\hline
\end{tabular}

This article gives an overview of diversity in the South African Department of Correctional Services and how it challenges the ministry of chaplains. The diversity is manifest in the religious affiliations of inmates, crime categories, various categories of offenders, and programmes and services as unpacked in this article. This article precisely aims to shed light on how the chaplaincy functions within the framework of corrections in South Africa and how the diversity of the inmates' population impacts on its theory and praxis. The Authors delineate the role that chaplains have to play to remain relevant to the correctional environment and accentuate the required empathic and non-judgmental stance by spiritual care personnel. Religious flexibility and adaptability is essential, as chaplains are managers of all religious activities. The article provides solid insights into what being a correctional chaplain in South Africa entails.

\section{Introduction}

Diversity in the South African Department of Correctional Services (DCS) stems from the fact that South Africa is a multicultural cosmopolitan country. The motto on the national coat of arms refers to 'unity in diversity'. This diversity is evident in all aspects of society, the church being one of them. Leaders from all walks of life, including political and traditional leaders, have to manage and work with this diversity in moving South Africa forward as a democratic country. According to the author's view, the clergy in different ministries are leaders, leading and guiding a diverse and varied congregation. This makes ministry in South Africa in the twenty-first century, especially ministry in various contexts, including the DCS, an interesting and challenging endeavour. This article is based or grounded on the chaplaincy in a correctional services setting.

Ministering to people in the South African context, in general, requires acknowledgement that God made us diverse and at the same time affords chaplains opportunities to learn from other people. Chaplains always have to be mindful of the diversity that prevails in their context. Pollard (1998) is correct when he states:

If God called you to be a missionary in another culture you wouldn't just hop in a plane and get started. Instead, you would begin by learning about culture and its worldview - what people believe why they believe it, and how you might be able to help them turn from false beliefs to the truth which is found through Jesus. This would take time and effort on your part. (p. 47)

Comprehending the culture and world views of different people is important for all those who offer pastoral care, including correctional chaplains.

In this article this notion is taken further. It is significant to take cognisance of the fact that society is characterised by extensive differences and conflicting opinions among people, even those in the same culture, same religion, and same denomination. Within the church there is a large degree of pluralism. There are differences in spirituality, disagreements on views about public issues such as abortion, homosexuality and the death penalty to name a few. There are churches and religious formations that are against the ordination and leadership of women. There are differences in views and behaviour about what is perceived to be right or wrong. There are also differences in terms of ethical norms and ethical practice. The authors' experience in the DCS has sensitised him to public perceptions regarding inmates and the whole correctional system. Inmates are in general viewed as bad people by individuals and communities due to the prevalence of crime in South Africa. Society believes that if offenders have a religion, then they all belong to Christianity and are hypocrites. The option of belonging to different faiths is disregarded. Stigmatisation becomes a challenge. Griffith (1993), an ex-offender, talks about stigmatisation under the topic 'the illusion of rehabilitation', where he has some criticism of the rehabilitative approach, and he remarks: 
Prisons can hardly make the claim that they prepare offenders for a return to society when imprisonment itself stigmatizes them so that they are sure to be rejected by society in return. (p. 46)

The above quote is some criticism that Griffith has, having been an offender himself who went through unfair judgment and human scrutiny that nearly destroyed his life. He raises a valid point to some degree as he further argues that stigmatising someone as a 'bad person' might actually be a powerful factor contributing to crime (Griffith 1993:46). However, his view cannot apply to all situations, as there is quantifiable success being accomplished in the rehabilitation of offenders in South Africa.

The DCS has addressed the imbalances of the past and allows people to enjoy the right to freedom of religion; this article also addresses the fact that religion is a constitutional imperative that is encapsulated in Sections 9(2), 15 and 31 of the constitution of South Africa. Evidence of this is manifested by the different faiths that come to correctional facilities countrywide on a daily basis to minister to offenders. An ideal situation would be to welcome and embrace all inmates who are released from the correctional centres especially by the religious fraternity; however stigmatisation remains a challenge especially within religious communities. The dissipation of stigma would necessitate robust engagement with broader society in terms of education and awareness.

\section{Diversity in religious affiliation}

Inmates enter the correctional system with various beliefs and faith backgrounds. Part of the chaplain's job is to be familiar with many different beliefs beyond their familiar faith, as well as to be prepared to research the other practices of a faith. According to a survey that was conducted by the C.B. Powell Bible School in conjunction with the University of South Africa in 2003, religious affinity within the DCS was as follows:

Inmates giving Christianity as their faith were by far the majority at $77 \%$, followed by a significantly smaller percentage of African traditional religion adherents at $11 \%$. Islam ranked third at $6 \%$, followed closely by an undefined group called 'others' scoring 5.5\%. Buddhism only scored $0.4 \%$ and Hinduism $0.1 \%$. Judaism scored $0 \%$ - the correlation between Judaism and a total lack of representation among offenders is worth noting.

The chaplain has to understand the needs of these different religions and refrain from imposing personal viewpoints upon the management of different activities. He or she has to be a religious programme manager and ensure that all inmates are afforded the same opportunity to practise their religion according to the prescripts of their church or faith. This requires extensive knowledge of standards, practices and interest in the diverse range of faiths and denominations as well as a thorough understanding of policies and procedures that govern all aspects of the correctional system. The spiritual care component makes provision for all these issues in the policy, policy procedures and policy guidelines of different faiths. The need for training in this regard cannot be overemphasised. The spiritual care policy procedures and policy guidelines address the great challenge of religious diversity as well as theological diversity. Religious diversity is easy to identify, whereas theological diversity is difficult to address because people in the same faith have different doctrines.

\section{Diverse crime categories}

Crime categories in the DCS show that most offenders are sentenced for aggressive offences (DCS Annual Report 2008/9). Aggressive offences are also in most cases contact crimes where there is an offender and an offended party. This depicts a society under siege being held hostage by those who have chosen the route of lawlessness. According to the DCS Annual Report of 2008/9, in correctional centres about $56 \%$ of offenders had committed aggressive offences; $22 \%$ had committed economic offences; $16 \%$ had committed sexual offences and $6 \%$ had committed other offences. The contributory factors, one may assume, could be unemployment and poverty.

In the light of this, the chaplains' ministry, in terms of programmes, has to be needs-based; hence the concept that spiritual care services have to develop and implement tailormade programmes because the one-size-fits-all approach will cause the department to fail to deliver on its core mandate, which is rehabilitation. It is quite evident from the

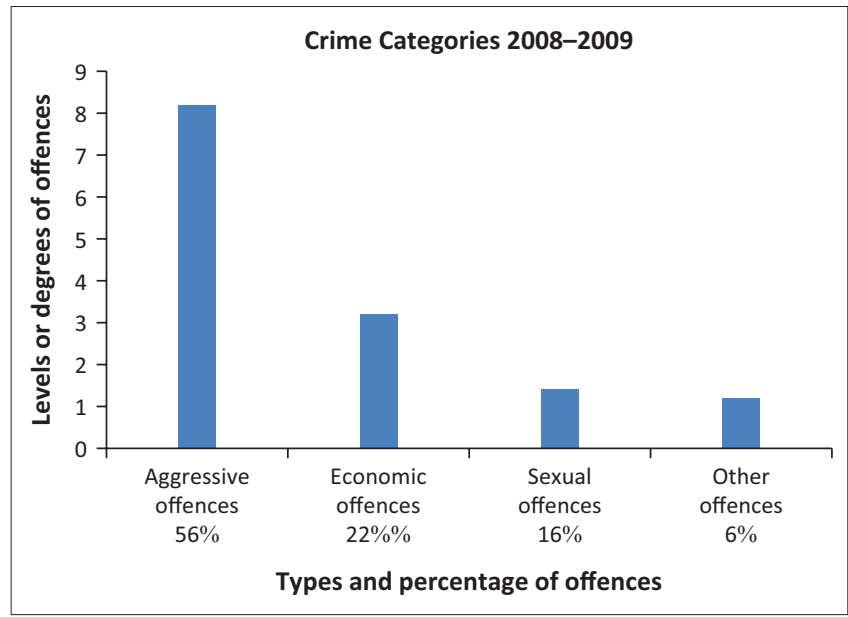

Source: Created by the author and information taken from the DCS report for 2008-2009 FIGURE 1: Diverse crime categories.

TABLE 1: Religious affiliation.

\begin{tabular}{|c|c|c|c|c|c|c|}
\hline African traditional religion & Buddhism & Christianity & Hinduism & Judaism & Islam & Others \\
\hline $11 \%$ & $0.4 \%$ & $77 \%$ & $0.1 \%$ & $0 \%$ & $6 \%$ & $5.5 \%$ \\
\hline
\end{tabular}

Source: Created by the author using information from the Religious Care Needs Survey, 2003 
above scenario that there is diversity in terms of offences that are committed by offenders when looking at crime categories. A chaplain needs to understand the criminal mind and all the factors that would reveal lack of discipline as the services and programmes are rendered. Engaging with offenders is a mammoth task that needs a correctional chaplain to hone skills that will ensure that all the categories are covered.

\section{Ministry to special categories of offenders}

The chaplains also minister to special categories of inmates in the DCS. The special categories of offenders comprise women, children, youth; detainees awaiting trial; people living with disabilities; and the elderly. The needs of these different categories of inmates are unique. According to the DCS annual report (2009/10:27) women, both sentenced and unsentenced, constituted $1.63 \%$ of the total inmate population in 2009/10. A key concern for the department is that, despite the seemingly low numbers of women who are in DCS facilities, the challenges faced by women are unique and require a special approach.

For example, one group facing unique challenges is pregnant women who give birth within the correctional facilities and others who enter correctional centres having just given birth. Special facilities that can accommodate mothers with babies are essential. The DCS facilities have been largely designed to accommodate men. Although the DCS is of the view that such women should not be incarcerated and their sentencing or implementation of their sentencing should be postponed, in the meantime, future upgrading and construction of facilities has to take the specific needs of women inmates into account. This notion would include the chaplaincy also, focusing on the spiritual needs of female inmates. The need arises to employ female chaplains to minister to the needs of incarcerated women.

The different categories of offenders in the custody of the DCS allow chaplains to work on different approaches and strategies in rehabilitation efforts and to see what works for which category.

The percentage of the inmate population classified as youth is a cause of real concern in South Africa. The 2009-2010 annual report reflected that the youth inmate population between 18 and 25 years as of 31 March 2010 was at 56520 against the total offender population of 164793 (DCS' Annual Report 2009/10:29). Of this total, approximately 58\% were sentenced and $42 \%$ were unsentenced. The largest numbers of youth offenders were between the ages of 22 and 25 , representing approximately $62 \%$ of the total number of youth offenders in correctional centres. Approximately $60 \%$ of sentenced youth offenders were classified in terms of security grading as medium, and maximum youth offenders constituted about $21 \%$. The majority of youth offenders who were incarcerated for aggressive crimes constituted about $50 \%$ of the total youth offender population. The DCS has
15 youth development centres, accommodating both medium and maximum security offenders. There are different sections for medium and maximum security offenders.

Considering the high percentage of incarcerated youth, the correctional chaplain has to be a mentor to young people. In this regard, the primary tasks of a mentor would be to build a relationship, develop life skills, provide resources and enhance communication. A chaplain has to be multiskilled to address all the areas in the development of young offenders. It is essential, the researchers believe, for the community to inculcate proper values to children at home, school and wherever they are, to become responsible citizens of South Africa who share the responsibility of making a difference in their society.

The DCS has placed rehabilitation of offenders at the centre of all its activities. Therefore, it is of paramount importance for chaplains to revisit their roles and align themselves with the strategic direction of the department. The White Paper on Corrections in South Africa (2005), which is a long-term strategic document, dictates that services and programmes have to be need-based (White Paper on Corrections in South Africa 2005:129). In the light of this, a programme design and development sub-directorate was established to address the identified gap in the spiritual care component. The 2003 survey, conducted by UNISA C.B. Powell Bible Centre on offenders' spiritual care needs, has indicated that in group sessions, topics that are prioritised are family life, self-image, discipleship, friendship, conflict, anger, loneliness, HIV or AIDS, aggression and work. This indicates that a person who ministers in a correctional context should have the ability to help people deal with these areas.

\section{Diversity in programmes and services}

Chaplains and spiritual care workers thus have to be diverse not only in terms of their approach to different denominations and faiths, but also in their ability to handle different life challenges. According to van Deventer, in 1986 there were 8 full-time chaplains and 1687 part-time workers (van Deventer in Sephton 1986:3). The figures have changed and will continue to change as the author writes this article; for example there are now 43 chaplains and 1452 spiritual workers. As mentioned before in this article, there are fulltime chaplains and part-time workers known as 'spiritual workers' who are rendering programmes and services to the inmates. Their participation has contributed to inmates having access to church or faith services by spiritual workers, including the following religious practices: Holy Communion, baptism, prayer meetings and celebration of holy festivals and days. Gerkin (1997) comments as follows on the impact of these rituals:

Some care can only be given the power of deep connection with communal meanings by way of corporate participation in the symbolical acts of receiving bread and wine; the laying on of hands and the administration of water of baptism. (p. 81) 
In a correctional environment some of these rituals mentioned by Gerkin have a deeper meaning in terms of pastoral care than just being regarded as religious practices. The inmates are allowed to participate in these rituals as long as they do not disrupt the smooth running of the correctional facility and also do not compromise security.

Gospel music choirs of inmates as an expression of spiritual praise are started by inmates themselves. Worship services that involve a lot of singing take place in correctional centres. It is interesting to note that Gerkin (1997) connects this to the expression of care, as he writes:

Singing together can express care and acknowledge our mutual need for care. Praying together can search for and celebrate the receiving of care that only God can provide. (p. 82)

This singing phenomenon is quite evident in correctional centres and is used as an indicator that some of the religious activities are successful, effective rehabilitation undertakings from a spiritual care perspective. These include rehabilitation through music to improve self-image, self-worth and selfconfidence.

Religious literature, including a book of faith (the Holy Bible, Holy Koran, etc.), is distributed to the inmates. The chaplain also has the key responsibility to facilitate the implementation of spiritual rehabilitation programmes. There are behaviour changes and moral development programmes such as the following:

- Heartlines programme (introduced in all management areas; 10673 inmates participated in the programme and completed in the year 2008-2009)

- restorative justice programmes, for example, the Sycamore Tree Programme (which is implemented in 12 management areas)

- lifestyle programmes such as the New Life Behaviour programme.

This example serves as an indication that there are intensive structured need-based programmes that are rendered to the offenders. There are currently 23 spiritual care programmes that are presented by spiritual workers and service providers nationally. The chaplain in this context also has to be familiar with the diverse interventions of the service providers with their own programmes, which enhance the rehabilitation concept of the department. This culminates in the need for the chaplains, as professionals, to continually develop their knowledge base, interact with different stakeholders and expand their learning into different areas that are within the scope of their work.

A diverse population presents chaplains with diverse problems. Beckford and Gilliat (2005:176) refer to the US Department of Justice (1195a:3), which states that meeting the demands posed by diversity is an 'integral component' of correctional management, and the chaplain stands at the forefront of leading institutions in 'a system-wide focus on enhancement of cultural; ethical and religious diversity issues'. The chaplains, as religious programme managers, have to ensure that all inmates are afforded opportunities to practise the faith of their choice and coordinate the various activities of those faith groups, including their programmes. This also demands an extensive knowledge of a diverse range of faiths and denominations therein, as well as the policies, policy procedures and guidelines that govern all aspects of the correctional system.

\section{Chaplains' ministry in the context of a diverse Department of Correctional Services}

The reader will recall that the word ministry is used both in a wider and narrower sense. In its wider sense, it refers to services rendered to God or people. In a narrower sense it denotes the officially recognised service of persons set apart by the church, for example through ordination (Ferguson, Wright \& Packer 1988:430). These etymological connotations are consistent in that the chaplains in this instance are called and ordained ministers seconded by their denominations or faith groups to minister in the correctional centres and to manage the spiritual care activities according to their key responsibility areas as alluded to before. This makes the chaplaincy a specialised field that has spiritual care as its theological base, though chaplains come from different faith and church traditions.

This article, as pointed out in the introduction, is based or grounded on the chaplaincy in a correctional setting and delves into ministry within this diverse context. In the DCS the chaplains' ministry focuses on inmates. Inmates are the chaplains' primary clients and the correctional officials are secondary clients, since ministry to them is done on an ad hoc basis. The ministry focus would also differ in terms of approach, as inmates' issues are also informed by their environments and depend solely on the influence that they get from people who volunteer at the correctional centres. The volunteers referred to are people from local communities. Their visits help inmates feel a sense of belonging to society. Correctional officials have both experiences; they come as workers to correctional centres, and when they leave the workplace they become members of the broader society outside.

The purpose of spiritual care is to render an effective service to offenders through needs-based programmes and services within a multidisciplinary context in partnership with the community, churches/faiths, faith-based organisations and other role players. Other professionals like teachers, nurses, social workers and psychologists add diversity to the leadership teams who also render services and programmes to offenders. The overarching aim of all who are involved in this undertaking is to take care, develop, rehabilitate and reintegrate the offenders back into society as faithful and law-abiding citizens. The chaplains have to know that this is not their turf alone but that other role players are equally important. 
It is pivotal to acknowledge that inmates have their own world views, as they come from different backgrounds in terms of culture, race, belief, faith and gender. Pollard (1998) has this to say about this challenge of different world views:

Now, of course most of us can't take time out to learn about all the worldviews that surround us. Many of us must learn as we get on with evangelism day to day. But if we are serious about reaching people with the gospel; we must also be serious about studying the worldviews that have been absorbed by the people we are trying to help. (p. 48)

This statement sensitises those involved in pastoral care to be contextual and relevant to the needs of people in different situations. This principle also applies to the correctional environment. It is, therefore, important not to be blinded by personal worldviews when called to minister in a correctional centre.

An introduction to ethnography as a pastoral practice in Moschella's approach would have chaplains learn from inmates, which would lead to improved pastoral care. In relation to pastoral practice Moschella explains that ethnography is a way of immersing oneself in the lives of people in order to learn something about and from them, especially in terms of understanding how they practise their faith (Moschella 2008:4). This would mean that what ethnography covers can in the long run be applied by correctional chaplains, who are expected to visit correctional centres to observe and evaluate how spiritual care work is done, as well as indicate if there is any impact of the services and programmes that are rendered by spiritual care personnel.

Offenders are convicted of different crimes, for example, rape, murder, burglary, theft and so on. This is in addition to the fact that they are different people, with different perceptions and perspectives on life. To deal with all the interventions in terms of rehabilitation, different approaches have to be taken, taking into consideration the type of crime that has been committed. The successful facilitation of a rehabilitation programme, therefore, depends on a fundamental theological and spiritual orientation of the chaplain or a pastor to address crime contributory factors presented by each inmate. The correctional services context, in fact, presents the chaplain with a unique opportunity and complex challenge to delve into and work with the diverse circumstances.

\section{The importance of an empathic and non-judgmental stance by spiritual care personnel}

Chaplains and spiritual care workers adopt an empathic and non-judgmental stance in order to facilitate the requirements of inmates. This empathic and non-judgmental stance is a necessary and basic starting point for chaplains and spiritual care workers, as they have to act primarily as facilitators and secondarily as religious guides. This role does not, however, make chaplains theological chameleons when looking at their context. In this regard, the facilitation role includes work such as the following.

- Making arrangements for religions and denominations different from that of the chaplain, to come into the correctional centre to minister to inmates who belong to that religious group or denomination.

- Speaki ng on behalf of the inmate to explain religious requirements to management, such as the religious diets (eating prescripts) of the Rastafarian or the fasting requirements of the Muslim. This is also one critical area within the DCS where there is transformation and various faiths are contributing to rehabilitation, which is the common goal.

There is something positive that religious structures can take from the correctional setting, and Yong (2008) has this to say about the interreligious dialogue that is taking place in the theological academy:

Christian-Muslim dialogue has produced expanded views of prophet-hood and scriptural revelation. Christian-Hindu dialogue has resulted in creative explorations of intertextual reading across religious conditions as well as fresh cross-religious Christological categories. Buddhist dialogue has called into question basic theistic assumptions across the board, given the non-theistic Buddhist worldview. Christian dialogue with Chinese religious traditions has opened up new possibilities for understanding Jesus Christ as Dao, the truth and the life. And this process of mutual transformation has occurred also in the Christian encounter with indigenous religious traditions in the Americas, in Africa, and in Australasias. Now in all these cases, the goal has never been to compromise Christian commitments but to engage in a dialogical quest for understanding from the standpoint of Christian faith. In the process, of course, the Christians have been enriched and transformed. (pp. 81-82)

This statement by Yong indicates that coexistence with other religious traditions cannot be ignored or underestimated. In the author's view this is what is happening in a correctional context, where chaplains have to play a critical role in terms of assisting line managers in the quest to facilitate responsible decision-making on inmates' spiritual matters. To do this efficaciously it is of pivotal importance that chaplains are able to ensure equal treatment for all and also demonstrate respect for the beliefs as well as the practices of inmates.

Beckford and Gilliat (2005) when remarking about multifaith say:

The starting point is that both 'multi-faith and multicultural' are loaded with positive connotations. They are not neutral terms of description. They usually imply that diversity of faith in communities and cultures is to be welcomed. In other words, these two concepts convey the notion of diversity; but they also go beyond it to suggest that diversity is a good thing. (p. 4)

This definition of the two terms by Beckford and Gilliat sheds light on the precept that the terms should not appear negative and fail to show the need for tolerance in religious and cultural diversity, especially in a correctional context. 
The DCS' population is multi-faith and multicultural, too. This stresses that facilitation, in an empathic and non-judgmental manner, includes religious flexibility and adaptability. This is at the very core of ministering within a diverse context.

Connected to religious flexibility and adaptability, the question is: how far should a correctional chaplain stretch himself or herself in terms of accommodating other religious groups and denominations without compromising his or her doctrinal stance? Yong further comes up with an interesting concept where he contends that there could be conversion in some respects to another religious tradition without leaving one's home faith; he calls that 'dual' or 'multiple religious identities' (2008:82-83).

Again, the author thinks that becoming a theological or religious chameleon is quite possible when one works in a multifaceted correctional environment, as the extent of flexibility by chaplains may not be always objective. However, this idea by Yong may not have a profound effect on the chaplains' role but opens a field that can be explored by other authors, especially in the South African context where sometimes there is a thin line between cultural and religious practices. This statement is useful in reminding chaplains that this concept has a very definite contemporary value and relevance.

\section{Inmate participation in programmes and services}

Rehabilitation is achieved through the delivery of key services to offenders, including both correction of the offending behaviour and the development of the human being involved. The correction of offending behaviour and development are two separate but linked responsibilities. Rehabilitation is achieved through interventions to change attitudes, behaviour and social circumstances. The desired outcome is rehabilitation and the promotion of social values and responsibility (White Paper on Corrections in South Africa 2005:72).

The above statement makes it imperative for the whole department to ensure that various activities are undertaken to deliver on the mentioned key areas.

According to the DCS' Annual Report for 2014/15 there were 159563 inmates (figures change on a daily basis) and $83.87 \%$ (133 826) of them participated in spiritual care programmes and services (DCS Annual Report 2014/15:54). The numbers keep on changing, as inmates are admitted daily at the centres as well as released daily from the correctional facilities. The percentage engaged in participation is an indication of the need for spiritual care services. This need further highlights and speaks to the demand for spiritual care workers and chaplains to be skilled at addressing the different needs of all these offenders, how to keep them interested and how to talk to them all. There is no doubt that with such a high participation rate, there is also a high variance rate. There are also challenges, of course, with such research showing that incarceration does not make people religious, and people who were never involved in religious activities before conviction remain the same.

The author in this article poses the following questions as he reflects on correctional chaplaincy in a diverse context.

- With such high levels of participation in spiritual care activities, what is the impact of chaplains?

- If so many offenders, as mentioned, are participating but none are converting or rehabilitated, what is the role of chaplains?

- How do chaplains interact with them on their lack of transformation?

Chaplains need to ask themselves the following fundamental questions.

- Are we doing what Christ in his second advent (the Parousia) will come to embrace?

- What can we do differently?

- What can we stop doing?

- What can we do additionally?

Furthermore, the other question that is of pivotal importance is as follows.

- What legacy are current chaplains leaving behind for those who will serve in their positions in future?

These questions add to what the authors raises about the vision and future of the DCS chaplaincy. By addressing these critical aspects raised in the above questions, chaplains in their developmental sessions will indicate what they need to enquire about, and the diverse nature of the DCS congregation affords them some unique opportunities to engage with such questions and also deliberate on the issues of this nature at national gatherings.

In conclusion, this article delved into the importance of how spiritual care needs are, or can be, met by chaplains in a diverse context like the DCS. This article has exposed a number of areas that depict diversity in the correctional centres that the chaplains have to be mindful of.

\section{Acknowledgements Competing interests}

The author declares that he has no financial or personal relationships that may have inappropriately influenced him in writing this article.

\section{References}

Beckford, J.A. \& Gilliat, S., 2005, Religion in prison: Equal rites in a multi-faith society, Cambridge University Press, Cambridge.

Department of Correctional Services, 2008/9, Annual Report, viewed 30 April 2016 from http://www.dcs.gov.za/Publications/AnnualReports.aspx

Department of Correctional Services, 2009/10, Annual Report, viewed 30 April 2016 from http://www.dcs.gov.za/Publications/AnnualReports.aspx

Department of Correctional Services, 2014/15, Annual Report, viewed 30 April 2016, from http://www.dcs.gov.za/Publications/AnnualReports.aspx 
Ferguson, S.B., Wright, D.F. \& Packer, J.I., 1988, New dictionary of theology, InterVarsity Press, London, England.

Gerkin, C.V., 1997, Introduction to pastoral care, Abingdon Press, Nashville, TN.

Griffith, L., 1993, The fall of the prison (Biblical perspective on prison abolition) William B. Eerdemans Publishing Company, Grand Rapids, MI.

Moschella, M.C., 2008, Ethnography as a pastoral practice (an introduction), The Pilgrim Press, Cleveland, $\mathrm{OH}$.

Offender' Spiritual Care Needs Survey, 2003, C.B. Powell Bible College and University of South Africa, UNISA, Pretoria.
Pollard, N., 1998, Evangelism made slightly less difficult, Inter-varsity Press, London.

Religious Care Needs Survey, 2003, Research project conducted by the UNISA CB Powell Bible Centre, UNISA, Pretoria.

The White Paper on Corrections in South Africa, 2005, Government Printers, Pretoria. Van Deventer, P.W., 1986, Gevangenispastoraat-prison ministry, in A.C Sephton (ed.), pp. 1-15, Pro Christo Publikasies, Bloemfontein.

Yong, A., 2008, Hospitality \& the other Pentecost; Christian practices; and the neighbour, Orbis Books, Eugene, OR. 